\title{
The effect of increasing the coinsurance rate on outpatient utilization of healthcare services in South Korea
}

\author{
Hyo Jung Lee ${ }^{1,2}$, Sung-In Jang ${ }^{2,3}$ and Eun-Cheol Park ${ }^{2,3^{*}}$
}

\begin{abstract}
Background: The Korean healthcare system is composed of costly and inefficient structures that fail to adequately divide the functions and roles of medical care organizations. To resolve this matter, the government reformed the cost-sharing policy in November of 2011 for the management of outpatients visiting general or tertiary hospitals with comparatively mild diseases. The purpose of the present study was to examine the impact of increasing the coinsurance rate of prescription drug costs for 52 mild diseases at general or tertiary hospitals on outpatient healthcare service utilization.

Methods: The present study used health insurance claim data collected from 2010 to 2013. The study population consisted of 505,691 outpatients and was defined as those aged 20-64 years who had visited medical care organizations for the treatment of 52 diseases both before and after the program began. To examine the effect of the cost-sharing policy on outpatient healthcare service utilization (percentage of general or tertiary hospital utilization, number of outpatient visits, and outpatient medical costs), a segmented regression analysis was performed.
\end{abstract}

Results: After the policy to increase the coinsurance rate on prescription drug costs was implemented, the number of outpatient visits at general or tertiary hospitals decreased ( $\beta=-0.0114, p<0.0001)$; however, the number increased at hospitals and clinics $(\beta=0.0580, p<0.0001)$. Eventually, the number of outpatient visits to hospitals and clinics began to decrease after policy initiation ( $\beta=-0.0018, p<0.0001$ ). Outpatient medical costs decreased for both medical care organizations (general or tertiary hospitals: $\beta=-2913.4, P<0.0001$; hospitals or clinics: $\beta=-591.35, p<0.0001$ ), and this decreasing trend continued with time.

Conclusions: It is not clear that decreased utilization of general or tertiary hospitals has transferred to that of clinics or hospitals due to the increased cost-sharing policy of prescription drug costs. This result indicates the cost-sharing policy, intended to change patient behaviors for healthcare service utilization, has had limited effects on rebuilding the healthcare system and the function of medical care organizations.

Keywords: Increased coinsurance rate, Prescription drug cost policy, Healthcare utilization, Outpatient visit, Medical costs

\footnotetext{
* Correspondence: ecpark@yuhs.ac

${ }^{2}$ Institute of Health Services Research, Yonsei University College of Medicine,

50 Yonsei-ro, Seodaemun-gu, Seoul 120-752, Republic of Korea

${ }^{3}$ Department of Preventive Medicine, Yonsei University College of Medicine,

Seoul, Republic of Korea

Full list of author information is available at the end of the article
} 


\section{Background}

Since South Korea established a national health insurance program in 1989, health expenditures and accessibility to healthcare and medical needs have rapidly increased [1]. In South Korea, total health expenditures accounted for $7.6 \%$ of gross domestic production in 2012 [2]. This total health expenditure is lower than the Organization for Economic Co-operation and Development (OECD) average of 9.3\%. However, the growth rate in health expenditure per person from 2001 to 2011 is higher than that of most OECD countries (South Korea: 9.3\%; OECD average: 4.0\%). Thus, achieving control over the constantly increasing health expenditure has become a key healthcare reform concern in South Korea [3].

There have been various discussions surrounding the financial stability of health insurance in South Korea. One of the proposed strategies is to build a sustainable healthcare system. To improve healthcare systems, simultaneous pursuit of three aims-improving the experience of care, improving the health of populations, and reducing per capita costs of health care-is required. The role of the South Korean government, as an integrator that accepts responsibility for these three aims, includes the redesign of primary care, population health management, and financial management [4]. In particular, the South Korean government attempted to improve primary health care and manage finances efficiently by assigning an appropriate role for medical care organizations according to size and function [5]. In South Korea, medical care is divided between clinical and hospital organizations by function, and hospitals are further divided into specialist and general hospitals according to structural characteristics. Medical law defines clinics (less than 30 beds) as centers treating outpatients and hospitals (more than 30 beds) as treating inpatients. General hospitals have more than 100 beds and at least 7 medical departments, including essential medical departments designated by medical law. Additionally, the Minister of Health and Welfare is able to specify tertiary hospitals as more specialist hospitals treating severe diseases compared to general hospitals with several requirements such as manpower, facilities, and equipment.

However, despite the use of this classification, individuals are able to choose any medical care organizations, from clinics in their community to hospitals [6]. Thus, the South Korean healthcare system contains inefficient structures that fail to adequately divide the functions and roles of medical care organizations. Accordingly, their functions overlap and all medical care organizations compete with each other, regardless of hospital type [7]. In addition, patients are focused on general hospitals in metropolitan areas despite having mild diseases and have to pay more for hospital services compared to clinic services. When evaluating diagnostic codes of outpatients according to hospital type, hypertension, diabetes mellitus, and acute upper respiratory tract infections, which are treatable in the primary healthcare setting, are the most frequent diseases treated in all hospital types. In addition, 44 tertiary hospitals ( $0.07 \%$ of medical care organizations) account for $23 \%$ of health insurance expenditure and this percentage is increasing [8]. Thus, in October 2011, the government reformed the policy for the management of outpatients visiting general hospitals for the care of comparatively mild diseases. This policy resulted in an increase in the existing $30 \%$ of coinsurance rate on prescription drug costs for 52 types of diseases to $50 \%$ in tertiary hospitals and $40 \%$ in general hospitals $[5,9]$.

In general, cost sharing, including coinsurance, copayment, and deductible, refers to any financing arrangement where the cost of the services used is supported in part by the user. The main objective is to prevent unnecessary utilization of health services and to stabilize insurance finances [10]. A further objective is to shift health care expenditures from public to private resources and secure additional finances to sustain the functioning of health services [11]. There have been many previous studies on cost sharing. The findings of the RAND Health Insurance Experiment and other studies of non-elderly insured populations reported that cost sharing reduced total health care spending and utilization without harming the health of individuals [12, 13]. However, some studies have reported higher cost sharing to be associated with adverse outcomes, particularly among vulnerable populations such as elderly and poor patients [14-16]. In studies that were not limited to patients with certain chronic illnesses, increased cost sharing was not found to be associated with increased number of outpatient visits, emergency department visits, or hospitalizations [17].

Previous research on cost sharing performed by South Korea found that low-income patients were more sensitive to cost sharing than high-income patients, and users of general hospitals were less sensitive to cost sharing than the users of clinics [18]. Furthermore, another study suggested that cost sharing among the elderly had little effect on controlling health care utilization [10]. However, some studies have demonstrated that cost sharing decreases medical costs and visit days per outpatient $[19,20]$. The results of studies regarding the effect of increasing the coinsurance rate of prescription drug costs-our policy of interest-were inconsistent [9, $21,22]$. In addition, few studies have considered individual characteristics, such as sex, age, and income, even where individual characteristics are important factors for healthcare utilization, particularly in South Korea due to free choice of medical care organizations and a payment system based on fee-for-service. Therefore, the purpose 
of the present study was to examine the impact of changing the coinsurance rate of prescription drug costs for 52 mild diseases on outpatient healthcare service utilization using nationally representative data.

\section{Methods}

\section{Study population}

The present study used National Sample Cohort data, including all medical claims, from 2010 to 2013 released by the National Health Insurance Service (NHIS), which consists of details of patient healthcare utilization. The data included approximately 100 million people sampled by sex, age, employment status (employed or selfemployed), income, and individual total medical costs. Our study population was defined as outpatients aged 20-64 years who had visited medical care organizations more than once, both before and after the policy change. for the treatment of 52 diseases, including acute bronchitis, gastritis, duodenitis, and hypertension. These 52 diseases are classified according to the International Classification of Diseases groupings (ICD-10) and details regarding each type and its description are presented in the Additional file 1. Additionally, the present study included only National Health Insurance (NHI) beneficiaries who were enrolled in health insurance provided by public sector. Health insurance in South Korea is classified into either NHI or Medical Aid. Individuals whose single-family household income is less than $\$ 600$ per month qualify for Medical Aid while others should join NHI. Since NHI and Medical Aid have slightly differing copayment systems, we included NHI beneficiaries only. The present study was approved by the Institutional Review Board, Yonsei University Graduate School of Public Health (2014-239). The requirement for informed consent from patients was waived as patient information was anonymized prior to the study analysis.

\section{Measures}

We used the proportion of general or tertiary hospital utilization, number of outpatient visits, and medical costs as dependent variables to reflect the shift of outpatients into hospitals or clinics from general or tertiary hospitals. All dependent variables were calculated in units of person-month. General or tertiary hospital utilization was defined as the proportion of general or tertiary hospital utilization among total healthcare utilization. The proportion of general or tertiary hospital utilization per month was calculated as (the number of outpatient visits into general or tertiary hospitals per person-month/the number of outpatient visits into total healthcare utilization per person-month $\times 100$. The numbers of outpatient visits and medical costs per person-month were analyzed by categorizing costs into general or tertiary hospital and hospital or clinic.
Medical costs indicated the total costs of visiting physicians and prescription drugs. The monetary unit of medical costs was KRW, with $1000 \mathrm{KRW}$ corresponding to approximately 1 US\$.

For the analysis of the relationship between the introduction of the policy and healthcare utilization, we adjusted for individual characteristics. Individual characteristics included age, sex, income, residence region, Charlson Comorbidity Index (CCI), and all cause admission during the previous year. Demographic factors, including age, sex, income, and residence region, are known to be associated with health care utilization [2325]. Further, health-related factors such as CCI and recently history of admission may affect the pattern of health care utilization [26-28]. Age in years was classified into five groups as follows; 20-29, 30-39, 40-49, 50-59, and 60-64. Regions were categorized into urban and rural. Income level was estimated using the average monthly health insurance premium. Individuals with NHI provided by their employer paid a monthly insurance premium according to annual salary, and those who were self-employed paid a premium according to their property value. Low-income was defined as the bottom 20 percentiles of health insurance premiums, middle-income was defined as the $20-80$ percentiles of the premiums, and high-income was defined as the top 20 percentiles of premiums. The CCI was used to account for the effects of comorbid disorders or diseases. CCI was calculated monthly according to Quan's methods [29]. Nineteen diseases were classified into scores of 1, 2, 3, and 6 [30]. The CCI was calculated from the sum of all scores and given extra scores in accordance with age. In the present study, CCI was grouped as scores of $0,1,2$, and 3 or over.

\section{Statistical analysis}

We examined the distribution of individual characteristics by analyzing their frequencies. Student's $t$-test was performed for dependent variables, proportion of general or tertiary hospital utilization, number of outpatient visits, and medical costs both before and after the introduction of the program. Segmented regression analysis of interrupted time series analysis was used to examine policy effects [31]. Our segmented regression analysis equation was:

$$
\begin{gathered}
Y_{i t}=\beta_{0}+\beta_{1} \times \text { time }_{t}+\beta_{2} \times 2011 \text { policy }+\beta_{3} \times \text { time after } 2011 \text { policy }+ \\
\beta_{4} \times \text { season }_{t}+X_{i t}+e_{i t}
\end{gathered}
$$

$Y$ dependent variables

$i$ each variables

$t$ time period

time a continuous variable beginning in January 2010 
2011 policy changing coinsurance rate on prescription drug cost in November 2011, a binary variable (0 before; 1 after)

time after 2011 policy a continuous variable beginning in November 2011

season seasonality (spring, summer, fall, winter)

$X$ independent variables

$e$ error term

In the present study analysis, the 2011 policy began in November 2011, as there was a 1-month-lagged effect after implementation of the policy. For the segmented regression analysis, the Generalized Estimation Equation (GEE) was used. PROC GENMOD was performed for the GEE with link identity, normal distribution, and type $=\mathrm{AR}$ (1). Repeated measures were considered and the unit of analysis was person-month. Subgroup analyses by income and sex were also performed. All statistical analyses were performed using SAS statistical software version 9.2. All calculated $p$-values were two-sided and considered statistically significant at $p<0.05$.

\section{Results}

Table 1 shows the general characteristics of the study population. A total of 505,691 outpatients were included in the analysis. The highest proportion was in the 50-59 years old group at 131,556 (26.0\%). There were 230,371 (45.6\%) men and 275,320 (54.4\%) women. More than half $(59.7 \%)$ were middle-income earners, lived in an urban area $(71.2 \%)$, and had 0 points on the CCI (64.4\%). The majority of the study population had no disability (96.4\%). A total of 48,922 (9.7\%) outpatients were admitted during the previous year. Based on the number of outpatients, the most common disease was acute bronchitis, unspecified (ICD-10: J20.9, 335,686 outpatients, 66.4\%). When viewed in terms of the total numbers of visits, patients with essential hypertension (ICD-10: I10) had the most visits to medical care organizations (1,638,083 cases, $13.6 \%)$.

The trends of each dependent variable before and after the policy are shown in Table 2. The proportion of general or tertiary hospital utilization was $5.9 \%$ before the 2011 policy and 5.4\% after the 2011 policy. The number of outpatient visits decreased in terms of general or tertiary hospital utilization per month but increased in hospital or clinic utilization after the 2011 policy (general or tertiary hospital utilization: 0.099 $>0.092, p<0.0001$; hospital or clinic utilization: 1.576 $>1.617, p<0.0001)$. Outpatient medical costs also decreased for general or tertiary hospital utilization per month but increased in hospital or clinic utilization after the 2011 policy (general or tertiary hospital utilization: 9273.8 - $>6316.4, p<0.0001$; hospital or clinic utilization: $44,935.1$ - >46,206.1, $p<0.0001)$. The trends of each dependent variable per month are shown in Fig. 1.
Table 1 General characteristics of the study population

\begin{tabular}{|c|c|c|}
\hline & Number & Percent \\
\hline \multicolumn{3}{|l|}{ Age } \\
\hline $20-29$ & 49,609 & 9.8 \\
\hline $30-39$ & 112,854 & 22.3 \\
\hline $40-49$ & 131,077 & 25.9 \\
\hline $50-59$ & 131,556 & 26.0 \\
\hline $60-64$ & 80,595 & 15.9 \\
\hline \multicolumn{3}{|l|}{ Sex } \\
\hline Men & 230,371 & 45.6 \\
\hline Women & 275,320 & 54.4 \\
\hline \multicolumn{3}{|l|}{ Income } \\
\hline Low (0-20\%) & 70,648 & 14.0 \\
\hline Middle (20.1-80\%) & 302,061 & 59.7 \\
\hline High (80.1-100\%) & 132,982 & 26.3 \\
\hline \multicolumn{3}{|l|}{ Region } \\
\hline Urban & 359,964 & 71.2 \\
\hline Rural & 145,727 & 28.8 \\
\hline \multicolumn{3}{|l|}{ Charlson comorbidity index } \\
\hline 0 & 325,786 & 64.4 \\
\hline 1 & 126,791 & 25.1 \\
\hline 2 & 41,673 & 8.2 \\
\hline $3+$ & 11,441 & 2.3 \\
\hline \multicolumn{3}{|l|}{ Disability } \\
\hline Normal & 487,371 & 96.4 \\
\hline Mild disability & 15,519 & 3.1 \\
\hline Severe disability & 2,801 & 0.6 \\
\hline \multicolumn{3}{|l|}{ All cause admission at previous year } \\
\hline Non-admission & 456,769 & 90.3 \\
\hline Admission & 48,922 & 9.7 \\
\hline \multicolumn{3}{|l|}{ Most frequent disease (ICD-10 code) } \\
\hline Acute bronchitis, unspecified (J20.9) & 335,686 & 66.4 \\
\hline Acute tonsillitis (J03.0 J03.9) & 201,650 & 39.9 \\
\hline Gastritis and duodenitis (K29.0 K29.9) & 192,444 & 38.1 \\
\hline $\begin{array}{l}\text { Acute upper respiratory infections of } \\
\text { multiple and unspecified sites (J06.0 J06.9) }\end{array}$ & 173,381 & 34.3 \\
\hline $\begin{array}{l}\text { Allergic contact dermatitis due to other } \\
\text { agents or unspecified cause }(\text { L23.8, L23.9) }\end{array}$ & 140,817 & 27.8 \\
\hline Total & 505,691 & 100.0 \\
\hline
\end{tabular}

Table 3 shows the results of the segmented regression analysis. The 2011 policy decreased the percentage of general or tertiary hospital utilization $(\beta=-1.6184, p<$ 0.0001 ). After the 2011 policy, the number of outpatient visits decreased for general or tertiary hospitals $(\beta=$ $-0.0114, p<0.0001)$ and increased for hospitals or clinics $(\beta=0.0580, p<0.0001)$. However, the number of outpatient visits in hospitals or clinics exhibited a 
Table 2 The trends of each dependent variable before and after the 2011 policy. Unit: Mean \pm SD

\begin{tabular}{lccc}
\hline & $\begin{array}{l}\text { Before intervention } \\
2010.1-2011.9\end{array}$ & $\begin{array}{c}\text { After intervention } \\
2011.10-2013.12\end{array}$ & $p$-value \\
\hline $\begin{array}{l}\text { Percentage of general and tertiary } \\
\text { hospital utilization }\end{array}$ & $5.921 \pm 0.390$ & $5.410 \pm 0.380$ & \\
General and tertiary hospital utilization & & & \\
$\quad$ Number of outpatient visits & $0.099 \pm 0.0001$ & $0.092 \pm 0.006$ & $<0.0001$ \\
$\quad$ Outpatient medical costs & $9273.8 \pm 542.8$ & $6316.4 \pm 366.5$ & $<0.0001$ \\
Hospital and clinic utilization & & $1.617 \pm 0.041$ & $<0.0001$ \\
$\quad$ Number of outpatient visits & $1.576 \pm 0.042$ & $46206.1 \pm 976.2$ & $<0.0001$ \\
Outpatient medical costs & $44935.1 \pm 1242.6$ & \\
\hline
\end{tabular}
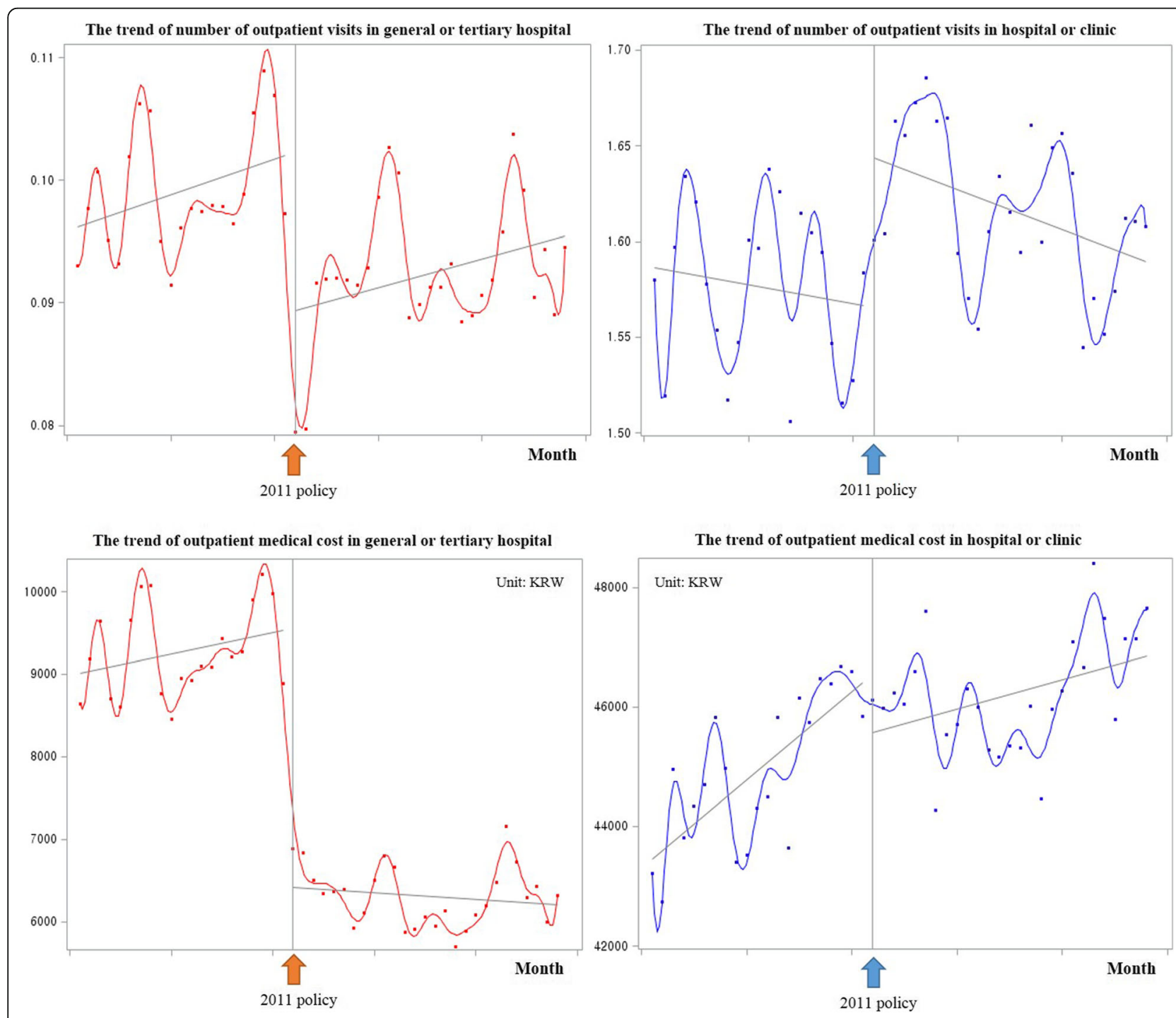

Fig. 1 The trends of each dependent variable for month 
Table 3 The results of the segmented regression analysis

\begin{tabular}{|c|c|c|c|c|c|c|}
\hline & \multicolumn{2}{|l|}{ Time } & \multicolumn{2}{|c|}{2011 policy } & \multicolumn{2}{|c|}{ Time after 2011 policy } \\
\hline & Estimate $^{*}$ & $p$-value & Estimate $^{*}$ & $p$-value & Estimate* & $p$-value \\
\hline \multicolumn{7}{|l|}{ Total } \\
\hline Percentage of general or tertiary hospital utilization & -0.0044 & 0.0658 & -1.6184 & $<0.0001$ & 0.0036 & 0.1786 \\
\hline \multicolumn{7}{|l|}{ General and tertiary hospital utilization } \\
\hline Number of outpatient visits & 0.0001 & 0.0034 & -0.0114 & $<0.0001$ & 0.0001 & 0.3159 \\
\hline Outpatient medical costs & 1.3140 & 0.7452 & -2913.4 & $<0.0001$ & -23.684 & $<0.0001$ \\
\hline \multicolumn{7}{|l|}{ Hospitals and clinic utilization } \\
\hline Number of outpatient visits & 0.0001 & 0.9998 & 0.0580 & $<0.0001$ & -0.0018 & $<0.0001$ \\
\hline Outpatient medical costs & 106.41 & $<0.0001$ & -591.35 & $<0.0001$ & -97.722 & $<0.0001$ \\
\hline \multicolumn{7}{|l|}{ Acute bronchitis, unspecified (J20.9) } \\
\hline Percentage of general and tertiary hospital utilization & -0.0086 & 0.0500 & -0.6044 & $<0.0001$ & 0.0167 & 0.0010 \\
\hline \multicolumn{7}{|l|}{ General and tertiary hospital utilization } \\
\hline Number of outpatient visits & 0.0001 & 0.5675 & -0.0060 & $<0.0001$ & 0.0001 & 0.0983 \\
\hline Outpatient medical costs & 6.5779 & 0.3676 & -1144.6 & $<0.0001$ & -9.5789 & 0.2411 \\
\hline \multicolumn{7}{|l|}{ Hospital and clinic utilization } \\
\hline Number of outpatient visits & 0.0023 & $<0.0001$ & 0.0110 & 0.0481 & -0.0041 & $<0.0001$ \\
\hline Outpatient medical costs & 127.14 & $<0.0001$ & -1057.7 & $<0.0001$ & -123.28 & $<0.0001$ \\
\hline \multicolumn{7}{|l|}{ Essential hypertension $(\mid 10.0,110.9)$} \\
\hline Percentage of general and tertiary hospital utilization & -0.0164 & 0.0001 & -1.0330 & $<0.0001$ & -0.0154 & 0.0029 \\
\hline \multicolumn{7}{|l|}{ General and tertiary hospital utilization } \\
\hline Number of outpatient visits & -0.0001 & 0.1233 & -0.0095 & $<0.0001$ & -0.0003 & $<0.0001$ \\
\hline Outpatient medical costs & -14.902 & 0.0543 & -2381.0 & $<0.0001$ & -51.712 & $<0.0001$ \\
\hline \multicolumn{7}{|l|}{ Hospital and clinic utilization } \\
\hline Number of outpatient visits & 0.0002 & 0.3478 & 0.0363 & $<0.0001$ & -0.0014 & $<0.0001$ \\
\hline Outpatient medical costs & 182.60 & $<0.0001$ & -877.34 & $<0.0001$ & -202.80 & $<0.0001$ \\
\hline
\end{tabular}

*Adjusted for age, sex, income, region, $\mathrm{CCl}$, disability, and all cause admission during the previous year

downward trend after the policy. Outpatient medical costs decreased in both medical care organizations (general or tertiary hospitals: $\beta=-2913.4, p<0.0001$; and hospital or clinic utilization: $\beta=-591.35, p<0.0001$ ). This trend continued to decrease over time. The percentage of general or tertiary hospital utilization by outpatients with acute bronchitis recovered $(\beta=0.0167, p=$ $0.0010)$, while that by outpatients with essential hypertension decreased $(\beta=-0.0154, p=0.0029)$ over time after the 2011 policy began.

After the policy began, the increasing coinsurance rate, number of outpatient visits, and outpatient medical costs in both medical care organizations demonstrated the same trend in the total population regardless of income and sex (Table 4). General or tertiary hospital utilization, including both the number of outpatient visits and outpatient medical costs, decreased; however, hospital or clinic utilization did not increase to the same extent as the decrease in general or tertiary hospital utilization. Rather, outpatient medical costs decreased. Unlike the results of the subgroup analysis by income, we identified that the absolute values of the coefficient for time after the 2011 policy were higher in women than in men, indicating women were more likely to be sensitive to the 2011 policy.

\section{Discussion}

Medical costs per visit for the same diagnostic code are higher in larger hospitals and are 3-4 times higher in tertiary hospitals than in clinics [8]. Thus, if outpatients are concentrated in tertiary hospitals, health insurance finances become an economic burden. In addition, since patients are less likely to visit clinics and small hospitals, the quality of care in clinics and small hospitals is reduced, which may lead to patient distrust of clinics and small hospitals. Patients will be then much less likely to visit clinics and small hospitals. Once this vicious cycle is repeated, financial difficulties, both in health insurance and in clinics or small hospitals, will further increase [32]. Tertiary hospitals may not be able to adequately perform their primary function of treating 
Table 4 The results of the segmented regression analysis by income

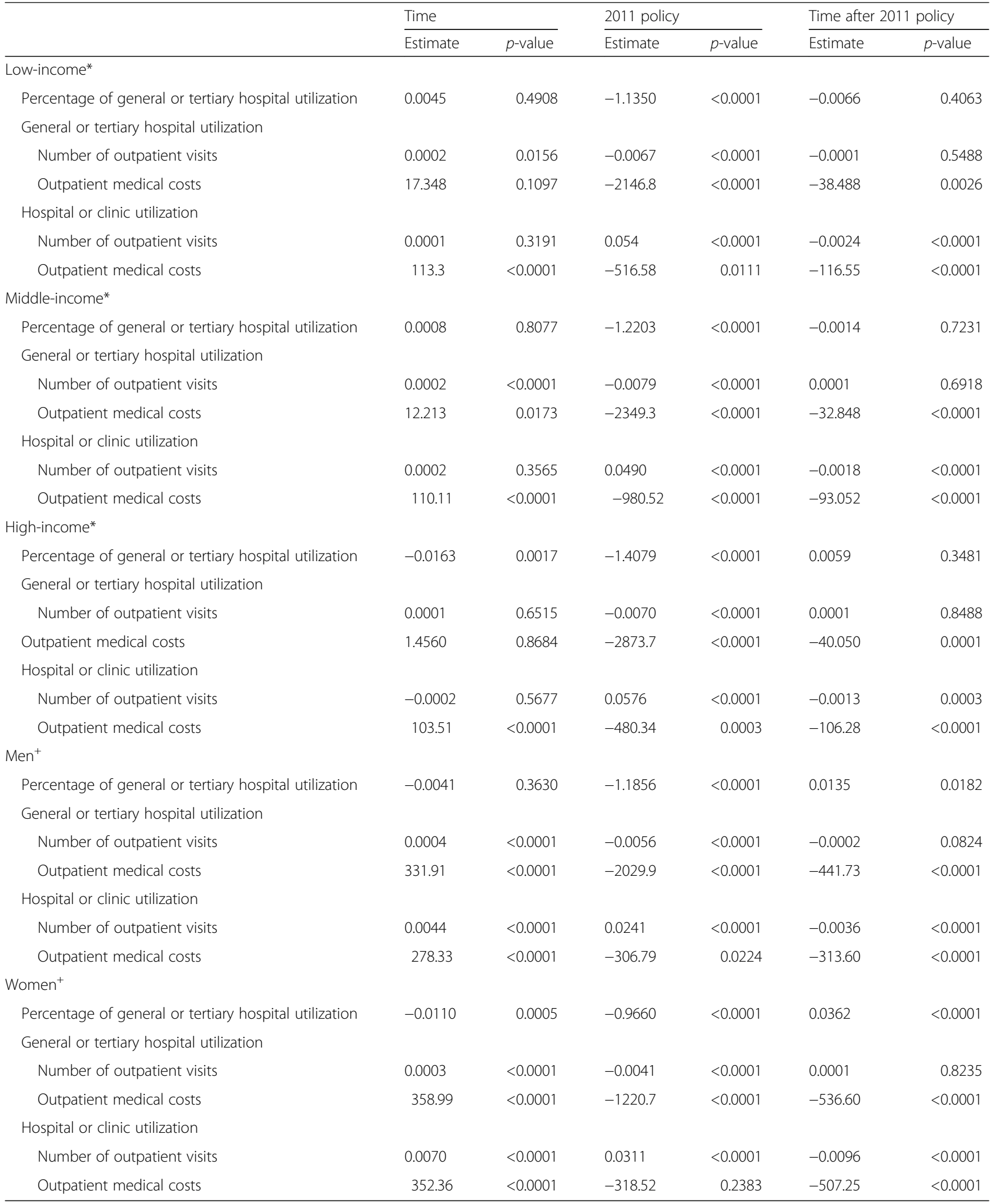

*Adjusted for age, sex, region, $\mathrm{CCl}$, disability, and all cause admission at previous year

${ }^{+}$Adjusted for age, income, region, $\mathrm{CCl}$, disability, and all cause admission at previous year 
severe diseases. Accordingly, outpatients presenting for 52 mild diseases paying prescription drug costs differently depending on the hospital type represents a potential method of resolving the above matters.

The findings of the present study indicate that changing the coinsurance rate on prescription drug costs was associated with changes in outpatient healthcare service utilization. The introduction of the 2011 policy decreased the number of outpatient visits in general or tertiary hospitals. The number of outpatient visits in hospitals or clinics increased with the introduction of the 2011 policy; however, it decreased over time after the 2011 policy. In addition, outpatient medical costs decreased in both general or tertiary hospitals and hospitals or clinics. Therefore, the 2011 policy, changing the coinsurance rate on prescription drug costs, partially shifted visits from general hospitals or tertiary hospitals to clinics.

Studies have reported that cost sharing reduces the needs of various health services and the burden of health insurance [17]. The reducing rate of outpatient medical cost increases for hospitals or clinics, despite the increase in the number of outpatient visits immediately after the 2011 policy, may be attributable to decreased pharmaceutical use, which could be caused by reduced unnecessary prescription drug treatment in the treatment intensity, although the decision making process on treatment intensity needs to be examined more carefully [33]. However, the effect of cost sharing is likely to involve side effects as our results demonstrate that the number of outpatient visits for general or tertiary hospitals tended to increase while that for hospitals or clinics decreased over time after the 2011 policy [21]. There are several possible explanations for these results. First, increasing the coinsurance rate from 10 to $20 \%$ may have been insufficient to prevent patients from excess visits to general or tertiary hospitals, and the effect of the costsharing policy may not have been maintained for a substantial period of time [34]. Second, increased cost sharing may be related to adverse events such as hospitalization and worsening clinical outcomes due to the decline in access to general or tertiary hospitals [33, 35]. Thus, the increase in hospitalization may have led to a decrease in outpatients, causing the number of outpatient visits for hospitals or clinics to decrease over time. Additionally, the present study demonstrates that both the number of outpatient visits and medical costs associated with hypertension decreased compared to other diseases after the 2011 policy in all medical care organizations. This observation may be explained in two ways. First, the policy increases the coinsurance rate for patients with specific diagnostic codes. Thus, outpatients with hypertension are able to continue visiting general and tertiary hospitals using other diagnostic codes such as for hypertensive heart disease (ICD-10: I11) rather than essential hypertension (ICD-10: I10). Alternatively, it is possible that hospitalization for hypertension increased over the study period [21].

We examined the effect of the 2011 policy on healthcare utilization according to income and sex via subgroup analysis. Income is an important factor for cost-sharing policies. We observed that women were more likely to be sensitive to the 2011 policy since the absolute values of the coefficient for time after the implementation of the 2011 policy were higher in women than in men. This result was consistent with those of previous studies [36, 37]. However, our study did not identify any direct evidence for a difference in healthcare utilization according to income level, despite previous reports that patients with lower income are more sensitive to the cost-sharing policy $[18,38,39]$. In the present study, the increased coinsurance rate did not have a consistent effect difference based on income. Thus, we were unable to evaluate price elasticity or moral hazards.

As a result, the 2011 policy did not control healthcare utilization and health insurance finance in the long term. It is important to observe the effect of increasing the coinsurance rate on prescription drug costs for 52 diseases in the future. In addition, establishment of the criteria for determining the primary diagnosis to prevent using another diagnostic code and follow-up investigations for continuously monitoring patients and hospitals are needed.

The present study has some strengths compared to previous studies. First, we used data from a nationally representative large sample size, which reflect the overall medical information of South Koreans. Such data are especially helpful in establishing evidence-based health policies. Second, to our knowledge, there are few previous studies from South Korea that have analyzed the correlations between policy introduction and healthcare utilization with consideration of individual characteristics. Although some studies have assessed policy effects, they have used the total sum of outpatient visits and medical costs per month rather than per person-month. Thus, we are able to provide more detailed information on the policy related to the coinsurance rate of prescription drug costs.

The present study also had some limitations related to limited data and methodology issues. First, there may have been other external factors, not considered in our study, which affected healthcare utilization. For example, in the case of hypertension, the South Korean government reformed the prices of existing drugs in April 2012 and revised guidelines restricting prescription for antihypertensive drugs in January 2013. In addition, some individuals, irrespective of the coinsurance rate, prefer general or tertiary hospitals over clinics. Thus, our 
results require careful interpretation. Further, since the most frequently treated diseases of the 52 are influenced by seasonal, socio-economic and demographic characteristics, and personal health status, healthcare utilization may have been affected [18, 40, 41]. Furthermore, detailed covariates related with each disease were not adjusted as we analyzed all 52 diseases, which included chronic diseases, as well as acute diseases. As each disease has different characteristics, other covariates may be needed. Furthermore, we did not assess the severity of disease as information related to this assessment was not available in the present study. However, we considered severity (in terms of $\mathrm{CCI}$ ) for a more detailed study. Last, hospital characteristics, including the quality of the offered services, were not captured in our study, and there may be hospital effects such as quality on healthcare utilization.

\section{Conclusions}

Our findings demonstrate that the introduction of the 2011 policy increasing the coinsurance rate on prescription drug costs decreased utilization of outpatient visits in general or tertiary hospitals. However, outpatient medical costs decreased in all medical care organizations. As we did not consider other external factors related to healthcare utilization in our analysis, it is not clear whether decreased utilization of general or tertiary hospitals transferred to demand for clinics or hospitals care of the 2011 policy. This result indicates that the price policy intended to change behaviors for healthcare service utilization had limited effects on rebuilding the healthcare system or the function of medical care organizations.

\section{Additional file}

Additional file 1: 52 diseases to apply the cost-sharing policy. (DOC $119 \mathrm{~kb})$

\section{Abbreviations \\ CCl: Charlson Comorbidity Index; GEE: Generalized estimation equation; ICD: International Classification of Diseases groupings; NHI: National Health Insurance; NHIS: National Health Insurance Service; OECD: Organization for Economic Cooperation and Development}

\section{Acknowledgments}

Both earlier version and revised version of this article have been reviewed by professional medical editing and proofreading services.

\section{Funding}

This study did not receive any external funding.

\section{Availability of data and materials}

Data is available from the Korean National Health Insurance Service (NHIS), however it is allowed only to researchers who propose a study subject and plans with a standardized proposal form and are approved by the NHIS review committee. Details of data releasing process are now available at http://nhiss.nhis.or.kr/bd/ab/bdaba000eng.do. The authors received permission from the NHIS to access and use their records containing the health insurance claim data.

\section{Authors' contributions}

All authors had full access to all of the data in the study and took responsibility for the integrity of the data and the accuracy of the data analysis. HJL designed the study, researched data, performed statistical analyses and wrote the manuscript. SIJ and ECP contributed to the discussion and reviewed and edited the manuscript. ECP is the guarantor of this work and gave critical revision for important intellectual content. All authors read and approved the final manuscript.

\section{Competing interests}

The authors declare that they have no competing interests.

\section{Consent for publication}

Not applicable.

\section{Ethics approval and consent to participate}

This study was approved by the Institutional Review Board, Yonsei University Graduate School of Public Health (2014-239), and the use of National Sample Cohort data was approved by the Korean National Health Insurance Service (NHIS) review committee. this study did not include informed consents from the patients, because datasets are completely anonymous and contain no personal information of participants.

\section{Author details}

${ }^{1}$ Department of Public Health, Graduate School, Yonsei University, Seoul, Republic of Korea. ${ }^{2}$ Institute of Health Services Research, Yonsei University College of Medicine, 50 Yonsei-ro, Seodaemun-gu, Seoul 120-752, Republic of Korea. ${ }^{3}$ Department of Preventive Medicine, Yonsei University College of Medicine, Seoul, Republic of Korea.

Received: 14 May 2016 Accepted: 7 February 2017

Published online: 20 February 2017

\section{References}

1. Kwon S. Thirty years of national health insurance in South Korea: lessons for achieving universal health care coverage. Health Policy Plan. 2009;24(1):63-71.

2. OECD. OECD Health Statistics: How does Korea compare?, OECD Publishing; 2014. http://www.oecd.org/els/health-systems/Briefing-Note-KOREA-2014. pdf.

3. OECD. Health at a Glance: OECD Indicators, OECD Publishing; 2013. http:// dx.doi.org/10.1787/health_glance-2013-en.

4. Berwick DM, Nolan TW, Whittington J. The triple aim: care, health, and cost. Health Aff (Millwood). 2008;27(3):759-69.

5. Ministry of Health and Welfare: Plan on the re-establishment of functions of health care institutions. Seoul; 2011

6. Lee J-H, Choi Y-J, Lee SH, Sung N-J, Kim S-Y, Hong JY. Association of the length of doctor-patient relationship with primary care quality in seven family practices in Korea. J Korean Med Sci. 2013;28(4):508-15.

7. Korea Institute for Health and Social Affairs. Trends and issues for improvement of Korea Healthcare delivery system. 2014. http://repository. kihasa.re.kr:8080/handle/201002/13872.

8. Research Institute for Healthcare Policy. Study for the reformation healthcare delivery system-focusingon the role of tertiary hospitals. 2010. http://www.dbpia.co.kr/Journal/ArticleDetail/NODE02471088.

9. Lee PH. Outpatient clinical trends in mild disease in the last five years. Health Insurance Review \& Assessment service Policy Brief. 2013;7(6):67-79.

10. Kwon MKS. The effect of outpatient cost sharing on health care utilization of the elderly. J Prev Med Public Health. 2010;43(6):496-504.

11. Ros CC, Groenewegen PP, Delnoij DM. All rights reserved, or can we just copy? Cost sharing arrangements and characteristics of health care systems. Health Policy. 2000;52(1):1-13.

12. Hsu J, Price M, Brand R, Ray GT, Fireman B, Newhouse JP, Selby JV. Costsharing for emergency care and unfavorable clinical events: findings from the safety and financial ramifications of ED copayments study. Health Serv Res. 2006;41(5):1801-20.

13. Goodell S, Swartz K. Cost-sharing: effects on spending and outcomes. Policy Brief. 2010;20:42-5. 
14. Zeber JE, Grazier KL, Valenstein M, Blow FC, Lantz PM. Effect of a medication copayment increase in veterans with schizophrenia. Am J Manag Care. 2007;13(6):335-47.

15. Trivedi AN, Moloo H, Mor V. Increased ambulatory care copayments and hospitalizations among the elderly. N Engl J Med. 2010;362(4):320-8.

16. Hartung DM, Carlson MJ, Kraemer DF, Haxby DG, Ketchum KL, Greenlick MR. Impact of a Medicaid copayment policy on prescription drug and health services utilization in a fee-for-service Medicaid population. Med Care. 2008; 46(6):565-72.

17. Goldman DP, Joyce GF, Zheng Y. Prescription drug cost sharing: associations with medication and medical utilization and spending and health. JAMA. 2007;298(1):61-9.

18. Kim J, Ko S, Yang B. The effects of patient cost sharing on ambulatory utilization in South Korea. Health Policy. 2005;72(3):293-300.

19. Hong S-W. The effects of copayments on health services utilization in the type I medicaid beneficiaries. J Korean Acad Nurs Adm. 2009;15(1):136-46.

20. Ko S, Kim J, Yang B. The effect of out-of-pocket price on ambulatory utilization. Korean J Health Econ Policy. 2002;8(1):1-27.

21. Byeon J, Ghang H, Lee H. Differential cost-sharing and utilization of outpatients care by types of medical institutions. Korea Social Policy Review. 2014;21(2):35-55.

22. Kim H-J, Kim Y-H, Kim H-S, Woo J-S, Oh S-J. The impact of outpatient coinsurance rate increase on outpatient healthcare service utilization in tertiary and general hospital. Health Policy and Management. 2013;23(1):19-34.

23. Kim C-W, Lee S-Y, Hong S-C. Equity in utilization of cancer inpatient services by income classes. Health Policy. 2005;72(2):187-200.

24. Bertakis KD, Azari R, Helms LJ, Callahan EJ, Robbins JA. Gender differences in the utilization of health care services. J Fam Pract. 2000;49(2):147.

25. Schappert SM, Rechsteiner EA. Ambulatory medical care utilization estimates for 2006. Natl Health Stat Report. 2008;6(8):1-29.

26. Young BA, Lin E, Von Korff M, Simon G, Ciechanowski P, Ludman EJ, Everson-Stewart S, Kinder L, Oliver M, Boyko EJ. Diabetes complications severity index and risk of mortality, hospitalization, and healthcare utilization. Am J Manag Care. 2008;14(1):15-23.

27. Struijs JN, Baan CA, Schellevis FG, Westert GP, van den Bos GA. Comorbidity in patients with diabetes mellitus: impact on medical health care utilization. BMC Health Serv Res. 2006;6(1):84

28. Valderas JM, Starfield B, Sibbald B, Salisbury C, Roland M. Defining comorbidity: implications for understanding health and health services. Ann Fam Med. 2009;7(4):357-63.

29. Quan H, Sundararajan V, Halfon P, Fong A, Burnand B, Luthi J-C, Saunders LD, Beck CA, Feasby TE, Ghali WA. Coding algorithms for defining comorbidities in ICD-9-CM and ICD-10 administrative data. Medical Care 2005:1130-39

30. Charlson ME, Pompei P, Ales KL, MacKenzie CR. A new method of classifying prognostic comorbidity in longitudinal studies: development and validation. J Chronic Dis. 1987;40(5):373-83.

31. Wagner AK, Soumerai SB, Zhang F, Ross-Degnan D. Segmented regression analysis of interrupted time series studies in medication use research. J Clin Pharm Ther. 2002;27(4):299-309.

32. Noh HK. Win-win growth of the medical profession: urgent tasks that can not be postponed for a moment. In: Vol. 11: Research Institute for Healthcare Policy Korean Medical Association. 2013.

33. Kan M, Suzuki W. Effects of cost sharing on the demand for physician services in Japan: evidence from a natural experiment. Japan and the World Economy. 2010;22(1):1-12.

34. Schreyögg J, Grabka MM. Copayments for ambulatory care in Germany: a natural experiment using a difference-in-difference approach. Eur J Health Econ. 2010;11(3):331-41.

35. Heisler M, Langa KM, Eby EL, Fendrick AM, Kabeto MU, Piette JD. The health effects of restricting prescription medication use because of cost. Med Care. 2004:42(7):626-34

36. Jang Y, Kim G, Chiriboga DA. Health, healthcare utilization, and satisfaction with service: barriers and facilitators for older Korean Americans. J Am Geriatr Soc. 2005;53(9):1613-7.

37. Lee S-YD, Tsai T-I, Tsai Y-W, Kuo KN. Health literacy, health status, and healthcare utilization of Taiwanese adults: results from a national survey. BMC Public Health. 2010;10(1):614.

38. Lostao L, Regidor E, Geyer S, Aïach P. Patient cost sharing and social inequalities in access to health care in three western European countries. Soc Sci Med. 2007;65(2):367-76.
39. Kiil A, Houlberg K. How does copayment for health care services affect demand, health and redistribution? A systematic review of the empirical evidence from 1990 to 2011. Eur J Health Econ. 2014;15(8):813-28.

40. Skriabikova O, Pavlova M, Groot W. Empirical models of demand for outpatient physician services and their relevance to the assessment of patient payment policies: a critical review of the literature. Int J Environ Res Public Health. 2010;7(6):2708-25.

41. Remler DK, Greene J. Cost-sharing: a blunt instrument. Annu Rev Public Health. 2009;30:293-311.

\section{Submit your next manuscript to BioMed Central and we will help you at every step:}

- We accept pre-submission inquiries

- Our selector tool helps you to find the most relevant journal

- We provide round the clock customer support

- Convenient online submission

- Thorough peer review

- Inclusion in PubMed and all major indexing services

- Maximum visibility for your research

Submit your manuscript at www.biomedcentral.com/submit
Biomed Central 